\title{
The Seedling Nursery Survey on Leyte Island, the Philippines
}

\author{
Nestor Gregorio ${ }^{1}$, Steve Harrison ${ }^{2}$ and John Herbohn ${ }^{2}$ \\ ${ }^{1}$ College of Forestry and Natural Resources, Visayas State University, Visca, \\ Baybay City, Leyte, the Philippines \\ ${ }^{2}$ School of Integrative Systems, The University of Queensland, Brisbane, \\ Qld 4072, Australia
}

\begin{abstract}
Private and government nurseries in the Philippines are not delivering high quality planting materials of a wide species base for smallholder forestry, tree farming and reforestation programs in the country. A project supported by the Australian Centre for International Agricultural Research (ACIAR) has been conducted to improve the operational effectiveness of the forest nursery sector in the Philippines. Surveys involving personal interviews of nursery operators, observations of the nursery design and facilities and assessment of seedling quality have been undertaken in Leyte (reported in this paper) and in Mindanao to provide baseline information for designing possible interventions. The Leyte study revealed that the low operational effectiveness of forest nurseries is a result of a combination of social, economic, technical and political factors. The majority of private nurseries are managed by resourceconstrained smallholders with little access to high quality seedling production technologies. Seedling production, both in private and government nurseries, is largely quantity-oriented and the pathway of high quality germplasm is not well developed. Government nurseries operate to provide free seedlings but this scheme results in crowding out the small-scale private nurseries, reducing the operational effectiveness of the private nursery sector. It appears that improving the operational effectiveness of the forest nursery sector in the Philippines requires policy changes to re-organize the operation of private and government nurseries and to strengthen the implementation of existing policies regulating the quality of planting stock from the forest nursery sector.
\end{abstract}

\section{INTRODUCTION}

Nursery seedling production is the most common practice for raising planting stock and the use of plants produced from the nursery is generally the most efficient and effective way of establishing a forestry plantation in the tropics (Evans and Turnbull 2004). In the Philippines, a variety of forest nurseries operate with varying objectives, resources and production technologies (Gregorio 2006). Despite the existence of government, community and private nurseries, the limited availability of seedlings has been regarded as a major impediment to the promotion of smallholder 
forestry in the country (Gunasena and Roshetko 2000; Herbohn et al. 2001; Mangaoang 2002).

Harrison et al. (2001) observed that the forest nursery industry in the Philippines is not well organized. Forest nurseries established by government agencies including the Department of Environment and Natural resources (DENR), exist to provide seedlings for smallholder tree farming activities and cater for the seedling requirement of the department's reforestation program. However, the majority of smallholders are producing seedlings for their own use and only a few have utilized the seedlings produced in government nurseries. This raises questions concerning the effectiveness of government nurseries in providing support to smallholders, especially with regard to provision of planting materials. Small-scale nurseries managed by community groups and private individuals are the main source of planting materials for the smallholder tree farmer community (Lawrence 1999; Emtage 2004; Cedamon et al. 2005).

With ACIAR support the Visayas State University (VSU) and The University of Queensland have implemented a project, entitled Enhancing Tree Seedling Supply via Economic and Policy Changes in the Philippine Nursery Sector (referred to as the Seedling Enhancement Project), in cooperation with the Department of Environment and Natural Resources (DENR) in Regions 8 and 10 and the World Agroforestry Center (WAC, formerly ICRAF). The primary objective of this project has been to improve the operational effectiveness of the forest nursery industry in the Philippines. In order to gain a comprehensive knowledge of the forestry nursery industry which would be an important basis for formulating measures to improve the operational effectiveness, it has been necessary to obtain up-to-date information on the operation and problems of the forestry seedling nursery sector.

This paper reports the development and results of the survey of nursery operators on Leyte Island in the Philippines. The objectives of the survey, selection of the target population, development of the questionnaire, and some of the survey findings are reported. Comments are made on how the survey information has informed other activities of the seedling enhancement project.

\section{RESEARCH QUESTIONS ADDRESSED}

In general, the seedling enhancement project is concerned with questions of how seedling quality can be improved, how supply of high quality seedlings can be sustained and how the financial sustainability of community and private nurseries can be improved. The surveys addressed general issues such as 'What are the profiles of firms in the industry?', 'What production technology is used in the industry?' and 'What is the current financial status of the industry?' This was done by seeking details on the history, capital infrastructure, management practices, production volume and costs and sales revenue, financial performance and future intentions of active government, community and private nurseries, and also details of nurseries not currently carrying out seedling production. 


\section{GENERAL RESEARCH APPROACH}

The research approach included a literature review, interview surveys of forestry seedling nurseries on Leyte Island in the Philippines in 2008, analysis of the survey data, and subsequent focus group discussions to present and critically evaluate survey findings. The nursery survey - conducted in 2008-09 - repeated and extended the 2003 study of Gregorio, reported in Gregorio (2006). The same three groups of nursery types (government, community and private) were included in the new survey. Both active and inactive nurseries in terms of seedling production were included.

In that seedling nurseries do not need to be registered with the DENR, no comprehensive list of nurseries was available as a sampling frame. The starting point for identifying the target population was the list of nurseries visited by Gregorio in 2003, which were identified through snowball sampling ${ }^{1}$. Additional nurseries were identified by the DENR and Department of Agriculture (DA) and through inquiries to selected local government units of some municipalities. A snowball sampling approach was again used to locate further nurseries.

All nurseries identified were included in the survey (i.e. a census rather than sample was conducted) because the overall population is relatively small (e.g. less than 100 nurseries on Leyte Island), and this lead to the collection of high quality data. It should be noted that when all members of a population are surveyed, the data cannot be subjected to statistical analysis ${ }^{2}$. Although a census is being conducted, the term survey is used in this paper, because this is the more widely understood term for data collection activities, and because the data collection method is essentially the same as in a sample survey.

\section{RESEARCH METHOD}

\section{Developing and Testing the Questionnaires}

Three sets of semi-structured questionnaires were developed for the survey interviews, one for each type of nursery ownership - government, community and smallholder nurseries. It has been a principle to use the same questions as far as possible for each nursery ownership group and survey location and where possible to use questions compatible with those of the 2003 survey $^{3}$.

The content of the questionnaires can be illustrated in terms of the various sections presented in Table 1. The initial section dealt with the operators and their financial resources. This was followed by sections eliciting information on germplasm pathway,

\footnotetext{
${ }^{1}$ The method involves asking the nursery operator about their knowledge of other seedling nurseries within the vicinity.

${ }^{2}$ Statistical inference techniques such as $t$ and chi-square tests and analysis of variance are designed to test hypotheses and thereby make inferences from a sample to a population, and rely on a measure of sampling error, which obviously is not relevant when data have been collected from all population members.

${ }^{3}$ Obviously, some differences in questions are necessary, e.g. it would not be relevant to ask government nursery operators about their sources of funds or other farming activities, or about their community organization.
} 
species preference and seedling marketing, nursery profile and details of seedling culture. A section was also created for nursery stock quality assessment.

Prior to conducting interviews, the questionnaires were tested to determine if the question structure and wording were clear enough to be understood by the respondents. Testing also provided practice for the field team in carrying out the interviewing process. Three nursery operators with similar conditions to the target respondents were interviewed using the three draft questionnaire types, and some questions were rephrased or deleted, and new questions added.

Table 1. Topics included in the questionnaires

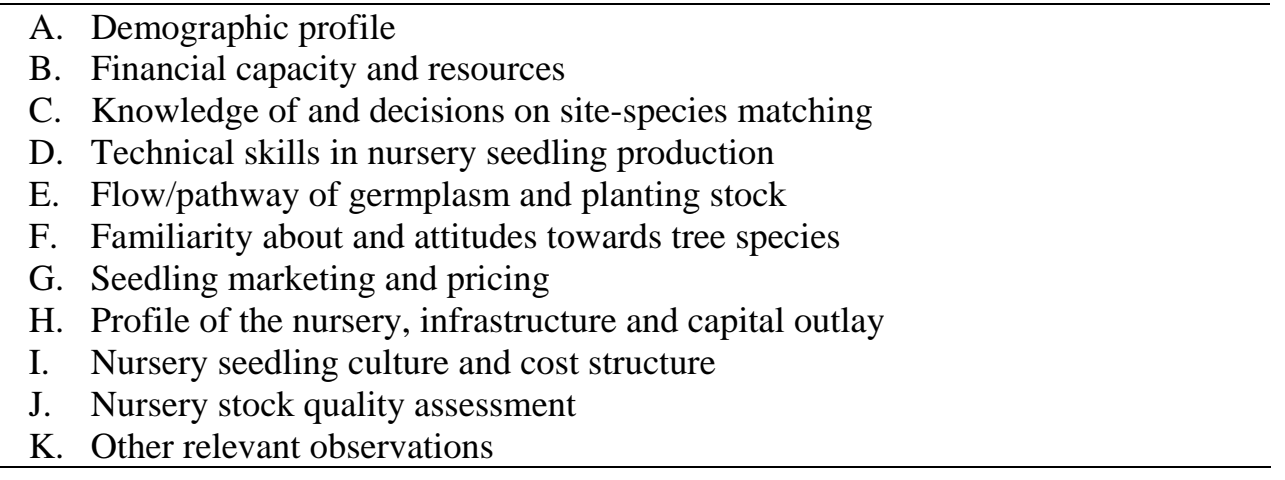

\section{Gatekeepers and Protocols Conducted Before Nursery Visits}

Prior to the face-to-face interviews, arrangements with regard to the mechanics of the interviews and their timing were made. Letters expressing the interest of the project to carry out the interviews and the reasons for conducting the survey were sent to all nursery operators. Consent of the nursery operators to conduct the proposed interviews was obtained either through phone calls or personal visits. After obtaining consent from the respondents, permission to conduct the survey was sought from gatekeepers including the municipal mayors and barangay captains, through personal meetings and discussions with the principal researcher and the interviewers.It was only after the approval of the gatekeepers was obtained that the survey interviews commenced.

\section{Interviewer Selection and Training}

Three teams of enumerators were formed to carry out the fieldwork with each team comprising three members. The enumerators included staff of the ACIAR project who had previous experience in carrying out socio-economic surveys. The ability to converse in local languages (Cebuano and Waray) was an essential criterion in the selection process. To avoid gender bias, each team was composed of both male and female members.

Prior to the fieldwork, a one-day orientation and training session was conducted to discuss with the enumerators the protocols in carrying out the survey, to expose them to the questions and to practice conducting the interviews. The enumerators also participated in testing the questionnaires and in identifying the required revisions. 


\section{Conducting the Fieldwork}

For the private nursery category, the household heads were interviewed. The person in charge of each nursery together with the president of the people's organization answered the questions in the communal nursery category. For government nurseries, the staff members designated to manage the nurseries were the respondents. In addition to personal interviews, the interviewers made observations of the standard of design and operation of the nurseries, drew sketches of the nurseries and determined the nursery location using a global positioning system (GPS). Destructive testing of seedlings was also performed to measure seedling quality parameters, including sturdiness (following Jaenicke 1999), basal diameter, total height, root-shoot ratio and root morphology. Any visually observable symptoms were recorded.

Each day after conducting interviews, the survey teams met and discussed their activity for the whole day. This was done to raise issues and clarify uncertainties of enumerators that would potentially hinder survey process, and to develop solutions to avoid experiencing similar problems on succeeding days of the survey period.

\section{Data Analysis}

The data collected were organized using Microsoft Excel and Access packages. Partial analyses were done using the Statistical Package for Social Sciences (SPSS). Data were transferred into Access for further organization and analyses, linking survey data with data from other research activities of the seedling enhancement project. A financial analysis of the nursery enterprise was carried out using data from the surveys and other sources.

\section{LINKS WITH OTHER PROJECT ACTIVITIES}

\section{Improving the Overall Understanding of the Nursery Sector}

The Leyte survey (together with that in Region 10) provided a wealth of information about the seedling nursery sector, which is highly useful for designing intervention measures to improve industry performance. A number of forms of analysis were conducted, for example, the locations of nurseries (GPS reading) and their sizes provide information on the accessibility of seedlings to smallholders.

\section{Informing the Policy Modelling}

Bayesian Belief Network (BBN) modelling operational effectiveness is being used by the seedling enhancement project for policy analysis to improve the operational effectiveness of the nursery industry. A key use of the survey findings is to provide information to update the model, making it a useful tool for policy simulation.

\section{Informing the Financial Modelling}

The questions relating to nursery capital outlays and operating costs (including unpriced resources such as the operators' labour) and revenue from seedling sales have been used in the development of financial models of seedling nursery operation. Financial modelling has been carried out for several scales of nursery operation to 
determine the extent of economies of scale, and the trade-off between seedling production cost and accessibility of nurseries to smallholder localities.

\section{Identifying Practices in Relation to Formulation of BMP, Benchmarking, Certification and Branding}

In that the seedling enhancement project is designed to improve the standard of operation of nurseries, some best management practice (BMP) guidelines to which nursery enterprises can aspire have been developed. These relate for example to: adopting systems which minimize root deformities; following practices to produce sturdy seedlings; discarding inferior seedlings; avoiding distribution of over-mature seedlings; and sun-hardening to improve seedling resistance to adverse growth conditions on outplanting. To the extent that nurseries collect their own seed, guidelines have also been formulated on how best to do this.

\section{RESULTS}

A total of 96 nurseries from 29 out of the 41 municipalities that comprise Leyte Island were included in the survey. The survey may not have included all nurseries, however, the rigour of the census that was done to identify the nurseries is a strong basis to claim that almost all of the nurseries on the island were included in the study.

\section{Nursery Type and Objective of Production}

The number of nurseries in each category was approximately equal. There were 35 individually owned nurseries, 33 managed by community organizations and 28 owned by government agencies. Individual nurseries are established and managed by individual farmers, usually with the help of their family members. These were usually established in response to the difficulty in obtaining planting stock from government nurseries. The nursery structure is usually temporary in nature, made of indigenous materials including tree branches or bamboo poles with coconut leaves as shade. This is generally established next to the house of the operator for ease of maintenance and security against pilfering and stray animals.

Communal nurseries are established by a group of people in the community. In most cases, the establishment is initiated through implementation of development projects such as Community-based Forest Management Projects and Reforestation Projects. In this type of nursery, the seedling production schedule, quantity of planting stock and species raised are jointly decided by the organisation and the supporting agency. In most cases, the participating members are paid for raising the seedlings and a formal protocol exists for the sharing of benefits including seedling sales revenue and future sales of timber from the communal plantation. The nursery is often located centrally within the community but in some cases, it is situated close to the communal planting site (which may be far from the barangay) for ease in transporting seedlings during field planting. The nursery structure is semi-permanent to permanent in nature.

Government-owned nurseries include those established by the DENR, DA, Local Government Units (LGUs) and schools. These are usually situated in major cities or towns. Seedlings are produced mainly for agency use and for free distribution to all interested parties. Experienced workers who are paid either on a contract or regular 
basis usually carry out the seedling production activities and the volume of seedlings produced is normally higher than in the individual and communal nurseries. With a well-established structure, this type of nursery is usually permanent in nature.

As indicated in Table 2, the prime reason for the establishment of private and communal nurseries is to grow seedlings either for own use or for sale, but the production in individual nurseries is highly flexible, for example private individual nurseries could readily shift their operation from a private use to commercial venture whenever there is a demand for seedlings. Communal nurseries are less flexible because their operation is guided by the management plan of the project implementation. The seedling production in most communal nurseries is funded as part of the implementation of development projects, and these nurseries are not readily able to sell their seedlings to other buyers. It is only after the culmination of the project that these nurseries could shift to a commercialized operation.

Table 2. Primary purpose of planting stock production

\begin{tabular}{lccc}
\hline \multirow{2}{*}{ Purpose } & \multicolumn{3}{c}{ Proportion of responses in each nursery group (\%) } \\
\cline { 2 - 4 } & Individual & Communal & Government \\
\hline Internal or personal use & 53 & 83 & 30 \\
For sale & 42 & 15 & 0 \\
For free distribution & 5 & 2 & 70 \\
\hline
\end{tabular}

Private nurseries operated with resources supplied by the nursery operator, although $27.6 \%$ received support in the form of seedling containers and seeds from supporting agencies. All communal nurseries received financial, technical and even marketing assistance from support agencies, particularly during the time of the operation of the forestry establishment project. However, after the culmination of the project, communal nurseries were left to operate without external support, and most were unable to continue their operations.

\section{Technical Skills in Seedling Production and Seedling Quality}

In general, operators of private nurseries and members of community organizations have low educational levels, which could be an important factor to consider in designing support measures particularly with regard to information, education and communication (IEC) programs. Only about 39\% of private nursery operators and $36 \%$ of managers of communal nurseries have completed education beyond secondary schooling. While a small proportion of private and community nursery owners and managers have obtained some form of tertiary education, these are not related to forestry.

Operators possess the basic skills required for seedling production. Most of the individual operators have learned these skills through trial and error. About $73.3 \%$ of private nursery operators have had no exposure to seedling production in the form of training sessions while $87.1 \%$ of the communal nursery operators have gained their knowledge from attending formal training sessions. All managers of government nurseries have attended formal training and almost all have completed a four year 
degree mostly in agriculture or forestry. While all nursery operators have a basic knowledge of seedling production, it is apparent that they still need further knowledge and skills to become experts in nursery management. Difficulties experienced in germinating seeds, inappropriate germplasm collection methods and the production of seedlings of low physical quality are manifestations of the need for further knowledge of seedling production. Nursery operators have strongly suggested hands-on training and visits to demonstration nurseries as methods to improve their knowledge and skills in forest nursery management.

An assessment of seedling quality from the three nursery categories reveals that the majority of the seedlings are of a low physical quality. Table 3 shows that $74 \%$ of seedlings from private nurseries, 69\% from communal nurseries and $71 \%$ from government nurseries have a sturdiness quotient of higher than six.

Table 3. Assessment of physical quality of sample seedlings from the nurseries

\begin{tabular}{lccc}
\hline Nursery category & $\begin{array}{c}\text { Sturdiness quotient } \\
\text { above six (\%) }\end{array}$ & $\begin{array}{c}\text { Imbalanced root- } \\
\text { shoot ratio (\%) }\end{array}$ & Presence of J-roots \\
\hline Individual & 74 & 80 & 41 \\
Communal & 68 & 86 & 54 \\
Government & 70 & 73 & 32 \\
\hline
\end{tabular}

According to Jaenicke (1999), seedlings with a sturdiness quotient greater than six are considered lanky and unlikely to withstand the high temperatures and low soil moisture at outplanting. Most of the seedlings also have an unbalanced root-shoot ratio and more than $30 \%$ in each nursery type have J-rooting.

Nursery operators are generally satisfied with the quality of seedlings they produce. About $73 \%$ and $86 \%$ of individual and communal nursery managers respectively believed that they are producing high quality seedlings. However, this impression is not consistent with the result of seedling quality assessment. This finding clearly indicates the lack of understanding of nursery operators regarding the concept of seedling quality, thus there is a need for effective capacity building measures regarding this aspect.

\section{Species Selection and Preference}

The objective of production is the initial basis for the choice of species to produce. For example, those nurseries that are selling seedlings concentrate on the demand for the species while those that raise seedlings for their own plantings place more emphasis on growth rate and timber quality of the species. As communal nurseries are project-based, the recommendations by supporting agencies and the requirements indicated in the project implementation plan are major considerations. Government nurseries normally have a particular list of species to produce for every growing season based on the demand by seedling users and species associated with their tree planting and reforestation programs.

While nursery operators have preferences about which species they would like to produce, the supply of germplasm and difficulties in producing the planting stock are 
major deciding factors in choosing the species to raise. Most often nursery operators eventually resort to the production of species for which mother trees are readily available, including mahogany and gmelina. These species are widely domesticated by smallholders and commonly planted in the reforestation projects of various government and non-government agencies. Table 4 lists the five most commonly produced species in the three nursery categories. Mahogany is the most widely propagated species, due to its high timber quality, relatively fast growth and readily accessible germplasm. Gmelina is also widely grown, because of its rapid growth and readily obtained seeds. Narra, molave and lauan are widely raised because of their excellent wood quality.

About 39\% of private nursery operators placed a high preference on indigenous species. This suggests that smallholders are interested in planting native trees. However, the lack of access to mother trees prevented them from producing most of the native species. Unlike the widely planted exotic species of gmelina and mahogany, native trees are less domesticated, thus germplasm is mostly sourced from mother trees in the native forest, which are scarce because they are preferred by timber poachers. Also, limited research has been done on native trees, thus information about their phenology is not readily available.

Table 4. List and ranking of species commonly produced in the three nursery categories

\begin{tabular}{lccc}
\hline \multirow{2}{*}{ Species } & \multicolumn{3}{c}{ Percentage of nurseries in each category } \\
\cline { 2 - 4 } & Individual & Communal & Government \\
\hline Mahogany (Swietenia macrophylla) & 75 & 68 & 75 \\
Gmelina (Gmelina arborea) & 54 & 45 & 46 \\
Mangium (Acacia mangium) & 29 & 55 & 25 \\
White lauan (Shorea contorta Vid) & 11 & 55 & 14 \\
Narra (Pterocarpus indicus) & 10 & 52 & 46 \\
\hline
\end{tabular}

\section{Germplasm Used in Seedling Production and Collection Methods}

Seeds and wildlings are the common germplasm used by nursery operators for seedling production. Seeds are often used for exotic species including mahogany, mangium and gmelina, and wildings for producing the native species. The location of mother trees in native forests makes it difficult for nursery operators to determine the fruiting season and the appropriate period to collect seed. With germplasm collection carried out late in the fruit maturity season, wildings are usually available instead of seeds. Inappropriate potting of wildlings often results in the production of seedlings of low physical quality, with an unbalanced root-shoot ratio and defective root form including J-rooting and coiling. If not allowed to stay in the nursery to recover fully from stress during the collection process, wildlings will have a high mortality rate after outplanting. Sy (1998) argued that the use of low quality planting materials produced from wildlings is one of the reasons for the failure of tree farming and reforestation projects in the Philippines. 
Of the nursery operators who collected seeds, 68\% indicated that seeds were usually collected from the ground rather than from the mother trees. The collection is also normally done from individual seed trees regardless of their physical characteristics. The 'collect what is available' practice is commonly adopted. According to Mulawarman et al. (2003), this practice is detrimental to the genetic quality of the resulting seedlings. Ideally, germplasm should be collected from selected mother trees that are growing far from each other to ensure high genetic quality and to promote high genetic diversity of seedlings.

\section{Sustainability of Nursery Enterprises}

The majority of the private (69\%) and communal (65\%) nurseries had ceased their seedling production at the time of the survey, most citing a lack of financial resources However, three communal nurseries have successfully shifted their operation to a commercial venture. Seedling sales allowed the members to continue to operate with revenue generation as the motive. Regular annual funding has enabled all government nurseries to sustain their operations.

Although the majority of private nurseries have ceased their seedling production, more than half $(58 \%)$ of operators emphasized that they are willing to resume their operation if there is a demand for planting stock. In contrast, communal nurseries are difficult to revive when the community organization is disbanded.

\section{Constraints in Nursery Operation}

The five most often stated constraints on operation for the three seedling nurseries categories are reported in Table 5. Lack of access to sources of germplasm is considered as the primary constraint experienced by individual and communal nursery operators. Inadequate funds are also experienced, which could be linked to the problem of low sales. Lack of labour and pilfering are constraints in government nurseries but are not major problems in private and communal nurseries. Unlike private nurseries which are mostly situated within the homestead of the nursery owner, and communal nurseries strategically located within the community to facilitate protection and maintenance, government nurseries are mostly situated next to the office of the agency, with no staff to oversee security, especially during weekends and holidays.

The problem of low sales in private nurseries could be affected by the free seedlings from government nurseries. Although there are no definite data showing the decline of seedling sales in private nurseries as a result of the free distribution program, it is expected that free seedlings from government nurseries will divert potential customers from buying seedlings from private nurseries. Without free transport, smallholders located distant from government nurseries are disadvantaged.

The size of the nurseries typically had not increased since they commenced operation. However, $69 \%$ of the private nurseries decreased the volume of seedlings produced before they totally ceased operation. The majority of the individual (87.9\%) and communal (83.9\%) nurseries have no business association or networks with other nurseries. Having connections with other nurseries could have improved the germplasm pathway and seedling sales. 
Table 5. Constraints in seedling production most often stated by nursery operators

\begin{tabular}{ll}
\hline Nursery category & \multicolumn{1}{c}{ Constraint } \\
\hline Individual & Access to seed sources \\
& Inadequate funds \\
& Low sales \\
& Difficulty in germinating seeds \\
& Unclaimed orders \\
& Access to seed sources \\
Communal & Inadequate funds \\
& Low sales \\
& Uncooperative members \\
& Seedling mortality \\
Government & Accequate funds to high quality seeds \\
& Low seed germination \\
& Lack of labour to work in the nursery \\
& Pilfering and damage by stray domestic animals \\
\hline
\end{tabular}

\section{Regulations to Control and Monitor Seedling Quality}

In cases where government seedling production is contracted by a private seedling producer, there are three criteria - total height, health and base diameter - by which seedlings are assessed before payment is made to the seedling producer. However, to maximize profit from the seedling production contract, private seedling producers use wildlings for common tree species including mahogany and narra, because holding time in the nursery to attain the required height and base diameter is shortened. While seedlings appear healthy and of suitable height and diameter for field planting, the short recovery period in the nursery results in underdeveloped root systems, assessment of root system condition not being a seedling assessment criterion.

The DENR has implemented two major policies to regulate the quality of seedlings from forestry nurseries, in the form of DENR Administrative Orders (DAO 95-9 series of 1995 and the most recent DAO 2010 -11). The former focuses on forest tree seed production, collection and distribution while the latter covers a wider scope to include forest nursery accreditation. The implementation of DAO 95-9 had little impact on the quality of planting stock from government and private nurseries. While this policy provides the protocol of producing and collecting high quality germplasm, managers of government and private nurseries are mostly using germplasm from inferior trees. The impact of recently implemented DAO 2010-11 on the overall forest nursery sector is still to be investigated. 


\section{CONCLUSION}

The forest nursery industry on Leyte Island is not effective in delivering high quality planting materials of a wide species base to tree farmers. The seedling production enterprise is hampered by the combination of social, technical, economic and political constraints. The majority of private nursery owners have low education levels, lacking knowledge on the attributes and importance of seedling quality and skills in the production of high quality planting stock. Seedling production is largely quantity-oriented. Lack of financial resources, limited access to germplasm of a wide species base and small market prevented most of private nurseries from sustaining their operation. There are existing government regulations on the quality of nurserygrown forestry seedlings but these have not as yet resulted in the improvement of the quality of planting stock. .

The current situation shows that there is no coordination between the operation of government and private nurseries. The program of free seedling distribution by government nurseries crowds out the operation of private nurseries. Most of the seedlings distributed by government nurseries duplicate the species sold in private nurseries. The continued operation of private nurseries is important because of declining funds for government seedling production, greater accessibility of private nurseries to the majority of tree farmers and the development of human and social capital of smallholders from the decentralized nursery operation.

There is a need to improve the organization of forestry seedling nursery production in the Philippines. The market for seedlings for industrial plantations, small-scale forestry and upland rehabilitation projects is evident but low sales remain a major constraint hampering the operation of most nurseries. There is a need to develop and institutionalize a policy that will regulate seedling quality and improve the financial viability of private nurseries. This intervention should be implemented in parallel with improved germplasm pathway and increasing the technical capacity of nursery operators.

\section{POLICY IMPLICATIONS}

The quality of seedlings is of utmost importance for the success of smallholder tree farming and large-scale reforestation programs. Ideally, only high quality seedlings, both physically and genetically, should be used. The use of high quality seedlings in tree farming and reforestation can be supported both at the national government level and the local nursery level. There is a need for a more effective implementation of national policies to control the quality of seedlings to be used in government-initiated reforestation projects and to regulate the quality of seedlings that will be produced by private and government nurseries. A nursery accreditation system which requires seedling producers to adopt a particular set of seedling production standards and a policy ensuring that seedlings for government reforestation programs are purchased only from BMP certified nurseries appears to be a sound option. At the local nursery level, capacity building of nursery operators and managers could be undertaken to improve their nursery management and seedling production skills. This could be undertaken together with providing an improved pathway of high quality germplasm. 
The shift to a decentralized management of forest resources in the Philippines has also promoted the seedling production activity to the local people. However, the presence of government nurseries is still important to support the sustainable operation of private nurseries. The current organization of the nursery sector in Leyte requires changes of functions and objectives, particularly for the government nursery subsector. Instead of negatively affecting the sustainability and financial viability of private nurseries due to the provision of free seedlings to prospective seedling buyers, government nurseries could support the private nursery operation by serving as demonstration sites showcasing seedling production technologies and becoming a conduit for distributing high quality seeds and extension materials for private seedling producers. Government nurseries could also facilitate the marketing of seedlings from private nurseries by serving as display centres and assisting in advertising private nurseries to potential seedling customers.

\section{REFERENCES}

CEDAMON, E.D. and N.F. EMTAGE. 2005. Present tree planting and management activities in four rural communities in Leyte Province. In: ACIAR Smallholder Forestry Project - Redevelopment of a Timber Industry Following Extensive Land Clearing: Proceedings from the End-of-Project Workshop (S.R. Harrison, J.L. Herbohn, J. Suh, E. Mangaoang and J. Vanclay, eds). 19-21 August, 2004, Ormoc City, the Philippines. pp. 37-50.

EMTAGE, N. 2004. An Investigation of the Social and Economic Factors Affecting the Development of Small-scale Forestry in Leyte Province, the Philippines. PhD thesis. The University of Queensland, Brisbane.

EVANS, J. and J. TURNBULL. 2004. Plantation Forestry in the Tropics: the Role, Silviculture and Use of Planted Forest for Industrial, Social, Environmental and Agroforestry Purposes. 3rd edn, Oxford University Press. Oxford.

GREGORIO, N, HERBOHN, J.L. and S.R. HARRISON. 2004. Small-scale forestry development in Leyte, the Philippines: the central role of nurseries. Small-scale Forest Economics, Management and Policy. 3(3): 337-351.

GREGORIO, N.O. 2006. Improving the Effectiveness of the Forest Nursery Industry in Leyte Province. PhD thesis. The University of Queensland, Brisbane.

GUNASENA, H. and J.M. ROSHETKO. 2000. After the Romance: Rethinking Community, Participation and Sustainability in the Philippine CBNRM. Ford Foundation, Manila.

HARRISON, S.R. and J.L. HERBOHN (eds). 2001. Socio-economic Evaluation of the Potential for Australian Tree Species in the Philippines. ACIAR Monograph 75, CSIRO Publishing, Melbourne. 192 pp.

HERBOHN, J.L., HARRISON, S.R. and B.J. NIXON. 2001. Social and economic factors affecting the use of Australian species in community based forest management in the Philippines uplands. In: Socio-Economic Evaluation of the Potential for Australian Tree Species in the Philippines (S.R. Harrison and J.L. Herbohn, eds). A report prepared for the Australian Centre for International Agricultural Research. Department of Economics, The University of Queensland, Brisbane.

JAENICKE, H. 1999. Good Tree Nursery Practices: Practical Guidelines for Research Nurseries. ICRAF, Nairobi. pp. 8-15. 
LAWRENCE, A. 1999. Tree domestication in Leyte and Bohol, the Philippines: the farmers perspectives. In: Domestication of Agroforestry Trees in Asia (J. Roshetko and D. Evans, eds). Proceedings of a regional workshop held in Yogyakarta, Indonesia. 4-7 November 1997. Forest Farm and Community Tree Research Reports, special issue. Taiwan Forestry Research Institute and Council of Agriculture, Taiwan, Republic of China; Winrock International, Morrilton, Arkansas, USA and International Centre for Research in Agroforestry, Nairobi, Kenya.

MANGAOANG, E.O. 2002. A forester's perspective of the socio-economic information requirements for forestry in Leyte. In: Socio-economic Research Methods in Forestry: A Training Manual (S. Harrison, J. Herbohn, E. Mangaoang and J. Vanclay, eds). Cooperative Research Centre for Tropical Rainforest Ecology and Management. Rainforest CRC, Cairns. pp. 1-14.

MULAWARMAN, ROSHETKO, J.M., SASONGKO, S.M. and D. IRIANTO. 2003. Tree Seed Management, Seed Sources, Seed Collection and Seed Handling: a Field Manual for Field Workers and Farmers. International Centre for Research in Agroforestry (ICRAF) and Winrock International. Bogor, Indonesia.

NIXON, B.J., HERBOHN, J.L. and S.R. HARRISON. 2001. Social and economic factors affecting community based forest management in the Philippines uplands. In: Socio-economic Evaluation of the Potential for Australian Tree Species in the Philippines (S.R. Harrison and J.L. Herbohn, eds). ACIAR Monograph 75, ACIAR, Canberra. pp. 111-124.

SY, M. 1998. Rehabilitation of natural logged-over forests: the Philippines scenario. Canopy International. 